() Open Access Full Text Article

REVIEW

\title{
Beyond Rheumatoid Arthritis Evaluation: What are We Missing?
}

This article was published in the following Dove Press journal:

Open Access Rheumatology: Research and Reviews

\author{
Gianna Espinoza' \\ Genessis Maldonado (iD ${ }^{2}$ \\ Jemina Narvaez $\mathbb{D}^{\prime}$ \\ Roberto Guerrero (iD) \\ Gustavo Citera $^{3}$ \\ Carlos Rios (D)

\begin{abstract}
'Rheumatology Department Universidad Espiritu Santo, Samborondon, Ecuador; ${ }^{2}$ Internal Medicine Department - Loyola MacNeal Hospital, Berwyn, United States of America; ${ }^{3}$ Rheumatology Department Instituto Nacional de Rehabilitación
\end{abstract} \\ Psicofísica, Buenos Aires, Argentina
}

Correspondence: Genessis Maldonado Tel +708-783-9100

Email genessis.maldonado@luhs.org

\begin{abstract}
Rheumatoid Arthritis (RA) is a chronic inflammatory autoimmune systemic disease that preferentially affects small and large joints with a progressive course and can become deforming and disabling. In recent years, much progress has been made in the evaluation of inflammation and disease activity, however, there are other factors that have a high impact on the quality of life of these patients, such as depression, anxiety, fatigue, sleep disorders, suicidal behavior, fibromyalgia, sexual activity, sarcopenia, frailty, cachexia and obesity that are not always evaluated by rheumatologists. This review shows that the evaluation and timely detection of these aspects in patients with RA could interfere with the prognosis and improve their quality of life.
\end{abstract}

Keywords: rheumatoid arthritis, depression, fibromyalgia, sexual activity, sarcopenia, quality of life

\section{Introduction}

Rheumatoid Arthritis (RA) is a chronic inflammatory autoimmune systemic disease that preferentially affects small and large joints with a progressive course; and without a proper diagnosis and treatment it can become deforming and disabling. ${ }^{1}$

The worldwide prevalence of RA is 0.4 to $1.3 \%$ and the incidence rate is 0.5 to $1 \%{ }^{2,3}$ and is considered one of the 50 most common diseases that contribute to global disability. ${ }^{4}$ According to a meta-analysis, RA may be affecting more than 1.3 million people in the United States and 15 million people worldwide. ${ }^{5}$ The prevalence of seropositive RA is estimated to be $50-70 .^{3}$ The prevalence is higher in women compared to men $(3: 1){ }^{6}$

RA is characterized by having extra-articular manifestations such as rheumatoid nodules, vasculitis, and systemic comorbidities such as cardiovascular diseases and pulmonary affectations. ${ }^{7}$ In addition, it is common to observe psychological or cognitive comorbidities such as anxiety, depression, loss of self-esteem, hopelessness and suicidal thoughts that affect the quality of life of patients. ${ }^{8}$

Likewise, somatic symptoms such as chronic pain, fatigue, sleep disturbances and loss of appetite are triggers that lead to sarcopenia, frailty and cachexia resulting in functional disability of patients. ${ }^{9}$ It has been shown that RA patients are at higher risk of presenting anxiety and depression, which worsens the state of their disease and also the response to conventional treatment. ${ }^{10}$

The importance of the correct evaluation and identification of these emotional disorders has been the subject of lesser research in the rheumatology field and many times they are underdiagnosed, causing the patient not to have optimal results in their clinical improvement or remission. ${ }^{1,6}$ 
The purpose of this review is to evaluate and identify psychiatric comorbidities associated with RA that lead to deterioration in the quality of life and, in turn, identify other manifestations that are not normally evaluated in the rheumatology consult such as sarcopenia, frailty, and cachexia, in order to optimize the clinical management.

\section{Search Methodology}

\section{Search Strategy}

A systematic search for documents was carried out in the following databases: PubMed, EMBASE, Cochrane Library. Keywords included "Rheumatoid Arthritis", "Depression", "Anxiety", "Suicidal thoughts", "Suicidal behavior", "Self-harm", "Fatigue", "Quality of Sleep", "Quality of Life", " Rheumatoid cachexia", "Obesity", "Fibromyalgia", "Sarcopenia", and "Frailty". The search strategy included free text and MeSH terms. Additional studies were sought from the reference list of certain primary studies and relevant reviews.

\section{Study Selection}

3963 articles were found, of which 139 were selected by peer review. The selection of articles was limited to studies and systematic reviews in humans and adults, in English and Spanish. Articles reporting associations between RA and depression, anxiety, fatigue, sleep disturbances, quality of life, suicidal behaviors, weight alterations, rheumatoid cachexia, obesity, fibromyalgia, sarcopenia, and frailty were selected. Articles comparing the mentioned variables with other rheumatological diseases that were not RA were excluded.

\section{Anxiety and Depression in RA}

Depression is considered a mental disorder characterized by sustained and long-term sadness accompanied by loss of interest in daily activities. It affects 1 in 5 people throughout their lives and is the leading cause of disability around the world. ${ }^{11}$ It is mostly associated with chronic diseases, autoimmune diseases or mood disorders such as anxiety. ${ }^{12}$ Although depression and anxiety are closely grouped, they are considered distinct conditions.

Among some of the complications or risk factors that RA presents, depression is one of the entities with the greatest complexity in its management and although its pathophysiology is not clearly explained, it has been shown that immune dysfunctions and inflammatory responses are related to the central nervous system
(CNS), linking these changes to neuro-psychiatric symptoms. ${ }^{13}$ The prevalence of depression in RA is approximately $38 \%{ }^{14}$ and is associated with increased disease activity, disability, increased morbidity and mortality, loss of social and recreational activities, ${ }^{15}$ lower adherence to treatment, sleep problems, higher risk of suicide, and lower probability of achieving complete remission of symptoms. ${ }^{16}$ In fact, it predicts incapacity for work in the early stages of the disease. ${ }^{5}$

A study of 1015 patients, estimated the degree of disagreement between RA patients and physicians at the time of diagnosing depression and/or anxiety; the percentage reported by patients was $22 \%$ and that reported by rheumatologists was $10.5 \% .{ }^{17}$ According to Zhang et al the prevalence of depression in patients with RA is estimated between 9.5 to $41.5 \%,{ }^{18}$ which is two to three times greater than the general population. ${ }^{7}$ Likewise, Intriago et al indicated that the most frequent comorbidity in patients with RA was depression in $42.5 \%{ }^{19}$ Peterson et al identified a prevalence of depression of $46 \%$ and anxiety of $24 \%$ in RA patients from the United States and European countries. It was evidenced that the highest prevalence of signs of anxiety and depression were found in those patients from ethnic minorities, with low economic income, low-class Latin American immigrants and with an added comorbidity (mostly hypertension). ${ }^{20}$

The concomitance between depression and autoimmune inflammatory diseases has been recorded for a long time, but has not yet been fully understood. ${ }^{13}$ However, it has been shown that there is a relationship between the activation of the peripheral immune response and changes in the central nervous system (Figure 1). ${ }^{13}$ Abdel-Ahad et al indicated that elevated serum levels of interleukin-1 receptor antagonist (IL1RA) and IL-17 in RA patients correlate with the severity of depression and other subsequent disorders such as insomnia, loss of appetite, anorexia, fatigue, decreased concentration, dysphoria, and libido. ${ }^{21}$ On the other hand, $\mathrm{Li}$ et al demonstrated an association between depression and disease activity using inflammatory markers and cytokines. Those patients with RA and high levels of interleukin-6 (IL-6) presented more depression compared to the control group, showing that pro-inflammatory cytokines contribute to the development of this entity. ${ }^{17}$

Besirli et al demonstrated using the Hospital Anxiety and Depression Scale (HADS), DAS-28 and Short Form36 (SF-36) that the worsening of the prognosis of patients 


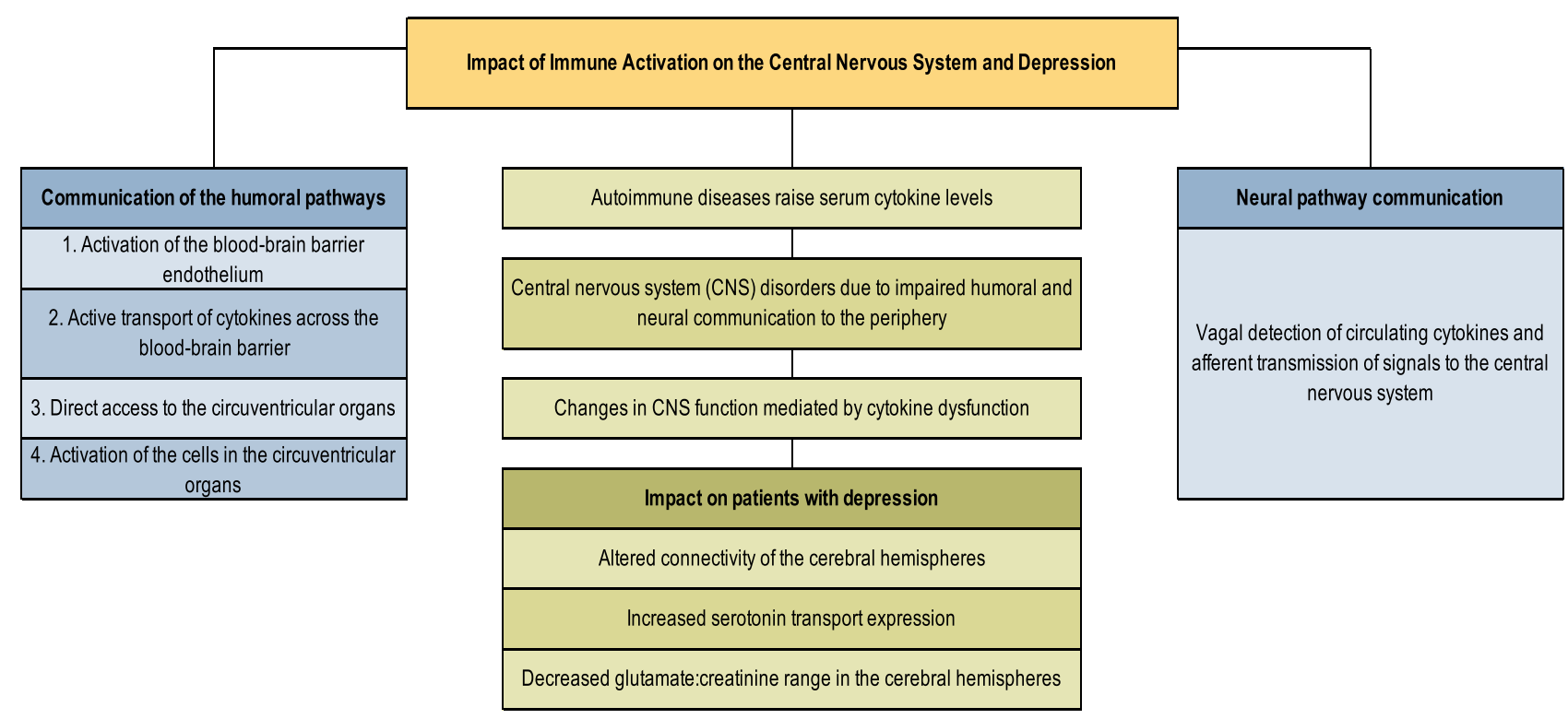

Figure I Impact of immune activation on the CNS and the relationship with depression.

with RA is related to the exacerbation of symptoms due to stress, which causes resistance to glucocorticoid, and subsequently to develop mood disorders such as anxiety, depression and in some cases suicidal ideas. ${ }^{6}$

Yaser et al concluded that RA activity is directly proportional to the development of depression and anxiety. ${ }^{22}$ According to Sleath et al only 1 in 5 patients with RA and severe depression agree to talk about their emotional disorder during the medical visit, the rest go unnoticed. ${ }^{23}$ Furthermore, social isolation due to joint deformities, selfloathing, low self-esteem, and anxiety are negative psychosocial factors involved in the depressive psychopathology of RA, while optimism and social support or support groups are protective factors against depression. ${ }^{21}$

\section{Suicidal Behavior in Rheumatoid Arthritis}

Suicidal behavior encompasses suicidal ideas or thoughts, suicidal plan, suicide attempt, and suicide. Suicidal thought is defined as an inclination or idea of self-harm or chosen behavior to end one's life, the suicide plan comprises the formulation of a method by which the person attempts to self-harm or die, the suicide attempt is determined as the act of self-harm with the purpose of dying and suicide is defined as the deliberate act of ending one's life and is the 13th leading cause of death globally. ${ }^{24}$

Besirli et al found a significant correlation between anxiety (HADS-A) [p <0.002] and depression (HADS-D) $[p<0.001]$ with the presence and intensity of suicidal behavior, using the Beck Scale for Suicidal Ideation
(BSSI), where the BSSI score was higher in patients with anxiety/depression, than in those who did not experience these emotional disorders. ${ }^{6}$ On the other hand, chronic diseases such as rheumatic diseases are also considered a risk factor for the development of suicidal behaviors. ${ }^{24}$ Marrie et al demonstrated that common mental disorders have a greater effect on mortality risk and suicide risk in RA than in depression alone. ${ }^{25}$

Kuriya et al showed that patients with RA tend to selfinjure 1.4 times more than those without the disease, the most common method used to injure themselves was through the ingestion of poisons followed by the use of sharp objects. ${ }^{26}$

Treharne et al showed that approximately $11 \%$ of patients with RA have manifested suicidal thoughts according to the Nottingham Health Profile (NHP), of which those who had a longer duration of the disease ( $>4$ years) were more likely to manifest them than those with an earlier disease course $(<2$ years $){ }^{27} \mathrm{Li}$ et al along with Treharne et al found that suicidal ideas were more prevalent in females in $11.7 \%$ to $14 \%$, compared to males with $0.0 \%$ and $3 \%,{ }^{27,28}$ the mean age was 56 years and the mean duration of the disease was approximately 10.9 years. ${ }^{28}$

Treharne et al indicated that depression detected by HADS is the most important factor of all, since $30 \%$ of patients with RA and depression experienced suicidal thoughts [OR 4.47, $\mathrm{P}<0.05] .{ }^{27}$ Hewlett et al identified that women around the world express that they have a flare of the disease in a similar way, they expressed it with phrases such 
as "I am in a lot of pain, I want to die" which reflects the presence of emotional distress as a consequence of the combination of physical symptoms and functional disability. This emotional distress is accompanied by irritability and frustration, despair and suicidal behavior. ${ }^{29}$

\section{Fatigue and Sleep Quality in RA}

Fatigue can be defined in two ways: physical fatigue, meaning physical exhaustion or reduced energy, and cognitive fatigue, which corresponds to alterations in thinking, memory or concentration. It is not considered a proper symptom to diagnose RA, ${ }^{30}$ little is known about its etiology ${ }^{31}$ and there is no clear definition accepted in RA. ${ }^{29}$ However, it is manifested in more than $50 \%$ of cases and interferes with both the work capacity and the patient's own burden of the disease. $^{30}$ Nikolaus et al indicate that severe fatigue manifests more frequently in females. ${ }^{32}$

In RA, fatigue is considered multifactorial and is associated with symptoms and signs of the disease, functional capacity, emotional, cognitive and social functioning. ${ }^{32}$ Nicassio et al proposed that certain factors directly contribute to the development of fatigue, such as disease activity, chronic pain and excessive inflammation, of which other contributing factors are triggered such as changes in mood and decreased quality of sleep (Figure 2). ${ }^{30}$

In patients with RA, sleep quality is altered by discontinuity or sleep deprivation and is related to depression, increased disease activity, exacerbation of pain perception and fatigue. ${ }^{33}$ Irwin et al indicated that the pathophysiology of sleep disturbance is given by an increase in the signaling of nuclear factor kappa-B (NF-kB) that induces the expression of IL-6 establishing a state of chronic hyperalgia, therefore, the relationship between sleep disorders and pain is bidirectional. ${ }^{33}$

A study in Poland demonstrated the prevalence between insomnia and depression in patients who have been diagnosed with RA, patients with $\mathrm{OA}$ and in patients from a control group. The results obtained for depression were $75.8 \%, 50 \%$ and $23.5 \%$ respectively and for insomnia $71 \%, 32 \%$ and $33 \%$. Which means that patients with a chronic underlying disease are the group with the highest risk of experiencing sleep disorders and consequently alterations in mental health. ${ }^{34}$

Rezaei et al showed that poor sleep quality occurs more frequently in RA patients due to increased disease activity, chronic pain, depression, and fatigue. ${ }^{35}$ Furthermore, according to Westhovens et al, Poor medical controls in these patients were significantly associated with an increase in daytime sleepiness and a deterioration in sleep quality. ${ }^{36}$

\section{Weight Changes in RA}

Chronic inflammatory and autoimmune diseases have a significant influence on body composition. ${ }^{37}$ In addition to joint damage and extra-articular manifestations in RA, other changes such as weight loss in the elderly, rheumatoid cachexia and obesity have been noted. Low BMI levels have been shown to be associated with decreased functional activity, fatigue, higher mortality, and adverse events in RA patients. $^{38}$

Persistent fatigue and decreased physical activity are reflected in the sedentary behavior of RA patients. According to Fenton et al sedentary lifestyle exacerbates inflammation levels worsening quality of life. ${ }^{37}$

Cachexia is a condition characterized by increased catabolic activity (expenditure of energy at rest) and loss of lean mass despite adequate food intake during a severe chronic disease associated with a high degree of inflammation. According to Challal et al two-thirds of RA patients were affected with rheumatoid cachexia, ${ }^{39}$ which is a clinical entity of RA recognized as the composition of a low muscle mass without weight loss and its global prevalence varies between 15 to $32 \%{ }^{40}$

Kremers et al indicated that the highest cardiovascular risk and highest rate of erosive disease in RA patients correspond to those with a BMI less than $18.5 \mathrm{~kg} / \mathrm{m} 2 .^{41}$ Despite the fact that the body disorders in RA have a vicious circle where there is a multifactorial contribution

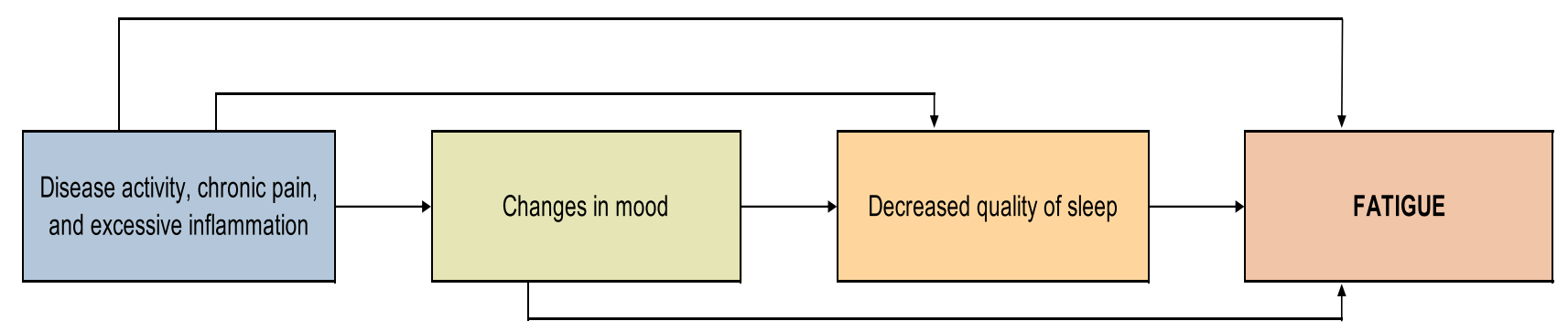

Figure 2 Factors that affect the development of fatigue. 
given by the activity of the disease, the nutritional diet and the chronic treatment with corticosteroids ${ }^{42}$ Santo et al indicated that rheumatoid cachexia may be induced by excess IL-1 and TNF-a and is associated with an increased risk of physical disability, morbidity and mortality. ${ }^{40}$

It is difficult to diagnose rheumatoid cachexia in the first visits because the loss of lean mass is compensated by the increase in body fat and the BMI is not altered further even if the patient has a normal $\operatorname{diet}^{39}{ }^{39}$ causing underdiagnoses as there is no consensus on clinical criteria. ${ }^{40}$

\section{Obesity and RA}

One in ten people in the world is classified as obese. ${ }^{43}$ According to the WHO, obesity is defined as a BMI greater than or equal to $30 \mathrm{~kg} / \mathrm{m}^{2}$, which is associated with a greater probability of developing chronic comorbid diseases such as diabetes mellitus, coronary heart disease, hypertension and RA. ${ }^{44,45}$ Obesity alone increases the production of pro-inflammatory cytokines in visceral adipose tissue, which rebounds on a chronic systemic inflammatory load in patients with RA. ${ }^{46}$

Kreps et al studied patients with RA who were also overweight and obese, they identified that weight loss greater than $5 \mathrm{~kg}$ is associated with a reduction in the clinical scale of disease activity (CDAI) by 1.15 points (95\% CI 0.42-1.88). ${ }^{47}$ Furthermore, they showed that those patients with weight loss at normal BMI levels are 3 times more likely to improve their disease activity. ${ }^{47}$

The impact of obesity on the response to treatment in patients with RA has been investigated in the last two decades, where studies indicate a negative effect in obese or overweight RA patients using cDMARDs with an inability to achieve a remission or low disease activity after 6 months of treatment. ${ }^{48,49}$ Furthermore, according to Ajeganova et al a study of 1596 patients with RA and obesity were associated with very high DAS- 28 scores and a lower chance of remission after a 9.5 -year follow-up. ${ }^{50}$ Thus, Passot et al, indicated that population pharmacokinetic studies have found that a high BMI is related to an accelerated clearance of anti-TNF agents, resulting in a decrease in the bioavailability of the drugs, ${ }^{51}$ therefore, the use of infliximab in this type of patient is less likely to achieve an appropriate remission of the disease. ${ }^{52}$

Many authors recommended developing personalized treatments based on predictive factors for the correct choice of a first-line therapy in patients with RA who have a high BMI. ${ }^{51}$

\section{Fibromyalgia in RA}

Fibromyalgia (FM) is one of the best-known comorbidities in Rheumatoid Arthritis. It is characterized by chronic pain due to a decrease in pain threshold, sleep disturbances and mood disorders. Its prevalence in patients with RA is approximately $21 \%$ with a range of $4.9-52.4 \%$, compared to the general population where the prevalence of FM is $2-8 \%{ }^{53}$ The concomitant presence of FM in RA patients alters the functional assessment. This is reflected in high levels of the disease assessment scales and increases the intensity of RA treatment, even with the most frequent use of biologics. ${ }^{54}$ Shresher et al studied 130 women with rheumatoid arthritis of which $40 \%$ met diagnostic criteria for fibromyalgia and in turn this group of patients had a longer duration of the disease, more pain measured using VAS and greater disease activity measured by DAS28, CDAI in comparison to patients without fibromyalgia. ${ }^{55}$

Chronic inflammation creates a transition from peripheral pain to central pain that is perceived as fibromyalgia symptoms. Pro-inflammatory cytokines TNF and IL-6 have been identified as involved in central pain processing and increased generalized sensitivity. ${ }^{55}$

The impact of fibromyalgia in patients with RA is important, since it has been shown that patients with fibromyalgia and RA have more depressive episodes, anxiety, panic attacks and post-traumatic stress than those patients with only RA. ${ }^{56-58}$ Pain is the most important independent factor together with the perception of disease activity in these patients.

Salaffi et al analyzed the influence of FM in achieving remission in patients with long-standing RA. They studied 117 patients with RA, of which $17 \%$ had fibromyalgia and none reached remission, the logistic regression analysis identified that the failure of remission measured by SDAI is due to the presence of FM. ${ }^{59}$ This behavior was similar in the ESPOIR study, in which patients with RA and FM did not reach remission and were shown to have a more aggressive disease activity than those who only had RA. ${ }^{60}$

Chakr et al showed that patients with RA and FM required higher doses of tricyclic antidepressants, leflunomide and prednisone compared to patients who only had RA, since the group of patients with concomitant FM had a moderate/high disease activity and a rate of $0 \%$ remission at the beginning of the study, however, during followup an increase in the doses for FM and RA was performed and an increase in the remission rate of $18.8 \%$ was 
observed. ${ }^{61}$ In addition, patients with RA and FM showed significant improvement on the DAS28 and Health Assessment Questionnaire (HAQ) scales when the treatment for FM was adjusted to the specific conditions of each patient.

\section{Sexual Activity}

The World Health Organization (WHO) recognizes sexual health as an essential part of general health and an important part of human well-being. ${ }^{62}$ According to the International Classification of Functioning, Disability and Health (ICF), sexual health encompasses 2 areas: intimate relationships and sexual functions, both of which can be affected in patients with RA. ${ }^{63}$

Sexual dysfunction is a common health conflict that affects up to $50 \%$ of the population and in most cases it can be correlated with age. ${ }^{64}$ Sexual dysfunction can be measured by scores; Sexual Health Inventory for Men for males, the Female Sexual Function Index (FSFI) for females $^{65}$ or the Changes in Sexual Functioning Questionnaire (CSFQ) for both.

In a study with 329 RA patients, the CSFQ score indicated general sexual dysfunction in $58.1 \%$ of the females and $33.8 \%$ of the males; Of which $37.6 \%$ of RA patients felt that rheumatoid disease had complicated their sexual life and $46.5 \%$ stated that fatigue is directly related to the negative impact on their sexual activity. ${ }^{66}$

There are few studies on the impact of RA on sexual activity, and it is not a common approach during routine clinical visits with the rheumatologist, since it is not part of the evaluation of the quality of life of patients with RA, ${ }^{62}$ but they frequently affect the decrease in sexual desire, difficulties to perform the sexual act and decrease in sexual satisfaction. ${ }^{67}$ These rheumatoid disorders can even lead to a negative body image and a deterioration of self-esteem. $^{62}$

According to Saad et al, the prevalence of sexual dysfunction in women with RA is $49.3 \%$ and is evaluated by the FSFI which measures 6 different areas of female sexuality: arousal, lubrication, desire, satisfaction, orgasm, and pain. ${ }^{67}$ In a cross-sectional study of 71 women with RA, all areas of the FSFI were significantly affected, especially orgasm, desire and arousal. In addition, sexual dysfunction was correlated with pain, the age of the patient $(\mathrm{p}=0.049)$, the age of the partner $(\mathrm{p}=0.013)$, number of nocturnal awakenings $(p=0.02)$, morning stiffness $(p=0.010)$, fatigue $(\operatorname{VASP})(\mathrm{P}=0.001)$ and joint tenderness $(\mathrm{p}=0.05)$. The age of the patients and pain were predictive factors in terms of alterations in sexual functioning. ${ }^{67}$

A comparative study between women with RA and healthy women in Turkey showed that sexual dysfunction was significantly worse in women with RA in the areas of lubrication, desire, satisfaction and arousal on the FSFI ( $p$ $=0.001)$. In addition, it was demonstrated that women with RA and sexual dysfunction also had alterations in the parameters of quality of life $(p=0001){ }^{64}$

Puchner et al used the Changes in Sexual Functioning Questionnaire-short form 14 (CSFQ-14) and found a strong association of sexual dysfunction in RA patients compared to the healthy control group ( $p<0.0001)$. On the other hand, a significant relationship was observed between BDI and sexual dysfunction. ${ }^{62}$

According to Twisttmann Bay et al, There is a large majority of men $(85.5 \%)$ and women $(93.5 \%)$ with RA who claim not to have discussed issues of sexual dysfunction with the health professional in the last 5 years. ${ }^{66}$ It is concluded that sexual dysfunction is more prevalent in women than in men with RA, affecting all areas of sexual function and is also forgotten in daily clinical practice by rheumatologists with clinicians.

\section{Sarcopenia in RA}

According to the European Working Group on Sarcopenia in Older People (EWGSOP), sarcopenia is defined as loss of muscle mass and its diagnosis should be based on the documentation of decreased muscle mass, low muscle strength and/or decreased physical performance. ${ }^{68}$ It is associated with disability and is an independent risk factor for falls.

Mochizuki et al studied the prevalence of sarcopenia in Japanese patients with RA, $29.6 \%$ of the population presented diagnostic criteria for sarcopenia. Among the associated factors were advanced age, body mass index (low weight, normal weight), elevated levels of c-reactive protein (CRP), and decreased bone mass. ${ }^{69}$

In RA, the cause of muscle loss is due to chronic inflammation, decreased physical activity, chronic pain, and increased energy expenditure during rest. A study by Giles et al showed that patients with RA have a higher prevalence of sarcopenia, ${ }^{70} 21.4 \%$ of women with RA and $33.3 \%$ of men with RA had sarcopenia compared to $7.7 \%$ and $22.2 \%$ in the control group, respectively. Women with RA demonstrated greater body fat at $42 \%$ compared to $38 \%$ in the control group. In addition, it was shown that women with RA and normal body weight were 3 times 
more likely to develop sarcopenia compared to the control group (OR 3.41 95\% CI: 1.51-7.69). ${ }^{70}$ Petermann-Rocha et al identified that women with RA and low weight were almost eight times more likely to have sarcopenia compared to individuals with normal weight (OR: $7.6095 \%$ CI: $6.08-9.50)^{71}$

Despite the fact that one of the diagnostic criteria for sarcopenia is age over 65 years, Mochizuki et al showed that having RA predisposes to the loss of muscle mass in young patients. They studied 87 patients with RA with a mean age of 51 years where $10.3 \%$ had sarcopenia, the factors associated with the development of sarcopenia by multivariate analysis were elevated disease activity and elevated erythrocyte sedimentation levels (OR 2.02 95\% CI. $1.04-3.91){ }^{69}$

Munro et al demonstrated an inverse correlation between C-reactive protein (CRP) levels and muscle mass, ${ }^{72}$ Interleukin $1 B$ is believed to cause a reduction in appetite and together with interleukin- 6 increases the liver's production of inflammatory markers. Dogan et al observed that women with rheumatoid arthritis and sarcopenia had higher CRP levels compared to the control group. $^{73}$ In addition, the Longitudinal Aging Study Amsterdam demonstrated the role played by interleukin- 6 and CRP, since they are associated with loss of muscle mass and muscle strength due to the fact that they increase proteolysis during muscle tissue synthesis. ${ }^{74}$

\section{Frailty in RA}

Despite improvements in therapeutic management of patients with RA, their physical disability and quality of life is markedly reduced, this is influenced by frailty. ${ }^{75}$ Frailty is a dynamic condition of greater vulnerability that restricts proper social, physical and psychological functioning. ${ }^{76}$ It is considered as a syndrome with multiple causes and factors characterized by sarcopenia, weakness, slowness, low activity and fatigue, which increases the vulnerability of the person to develop greater dependency and/or death. ${ }^{59}$

The prevalence of frailty in RA patients has a considerable impact, ${ }^{59}$ according to Salaffi et al, young patients with RA presented frailty in $2.5 \%$ and $36.4 \%$ in older adults with RA ( $p<0.001)(98)$. Likewise, the prevalence of pre-frailty in young patients with RA was $11.5 \%$ and in the elderly $57.9 \%(\mathrm{p}<0.001) .{ }^{59}$

Among adults with RA, being frail compared to being robust showed a significant difference in a worsening of physical function through the scores of the Valued Life Activities (VLA) disability scale $(p<0.01) .{ }^{75}$ In 2019 , the same authors identified that initial frailty in patients with RA can predict an increase or worsening of HAQ $(95 \%$ CI, $\mathrm{p}<0.01$ ), where fatigue is an important contributor to the final effect. ${ }^{77}$

According to Briot et al frailty accompanied by systemic osteoporosis and increased fracture rates has been described in chronic inflammatory diseases with joint involvement such as RA. ${ }^{78}$ In fact, RA is included in the Fracture Risk Assessment tool (FRAX) fracture prediction algorithm. Due to systemic inflammation, an activation and release of pro-inflammatory cytokines is generated that affect different pathogens and tissues. ${ }^{78}$ According to Guler-Yuksel et al, this inflammatory process affects several organs, including bone tissue, presenting as local bone erosions and localized and general periarticular bone loss, which is one of the main early extra-articular complications of RA. ${ }^{79}$

Inflammatory changes in bone tissue double the risk of vertebral, hip, and other fractures, compared to healthy controls of the same age. ${ }^{78}$ The bone fragility found in patients with RA is linked to general factors such as age, female sex, low BMI; and specific factors for RA such as the positivity of RF or anti-CCP, activity and duration of the disease, immobility, risk of falls, systemic inflammation, sarcopenia and the use of glucocorticoids (Figure 3). ${ }^{78} \mathrm{In}$ addition, it is estimated that mortality may be premature in

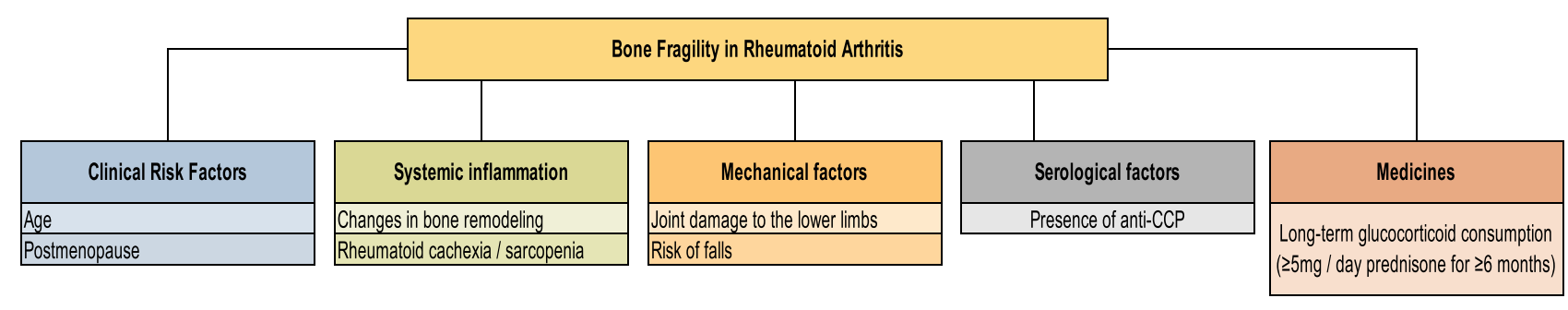

Figure 3 Factors influencing bone fragility in patients with RA. 


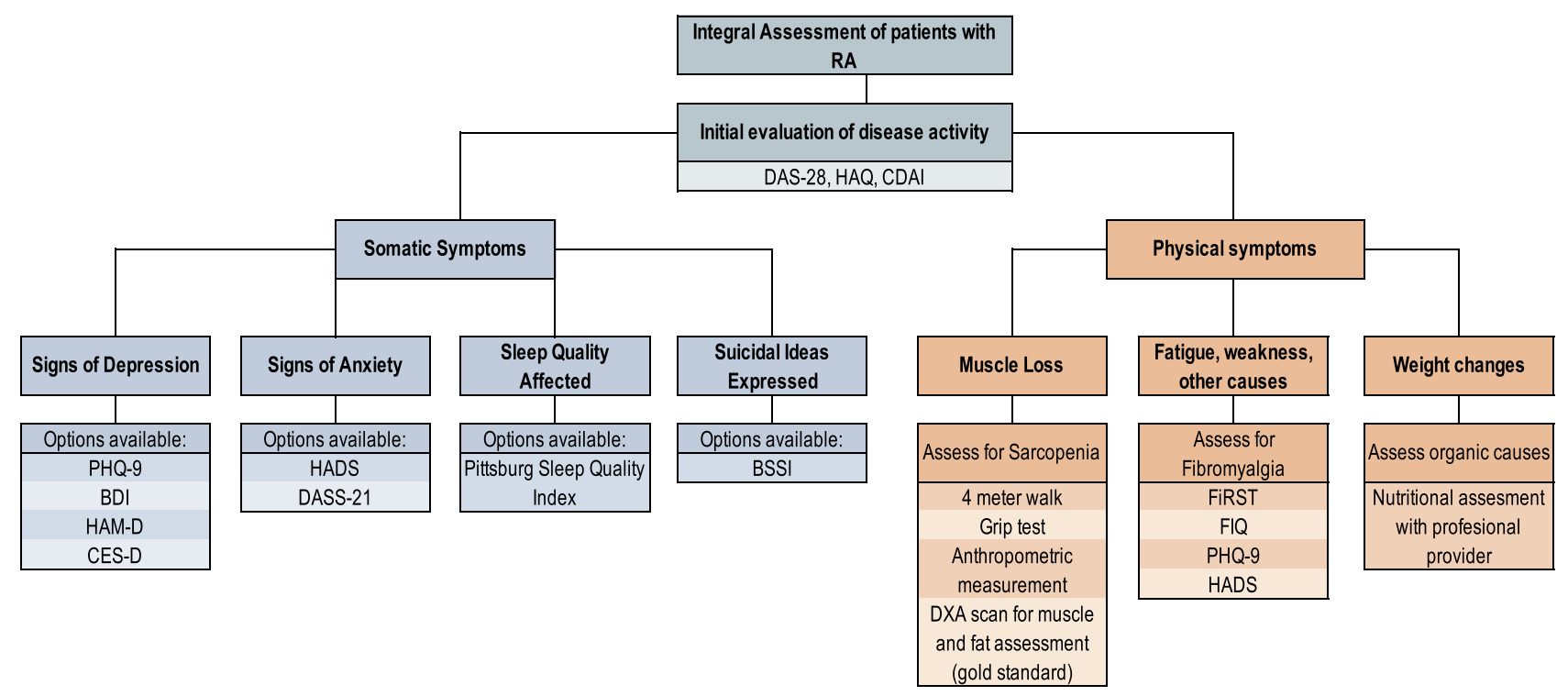

DAS-28: Disease Activity Score-28, Health Assessment Questionnaire, CDAl: Clinical Disease Activity Index, PHQ-9: Patient Health Questionnaire, BDI: Beck Depression Inventory, HAM-D: Center for Epidemiologic Studies Depression Scale, HADS: Hospital Anxiety and Depression Scale, DASS21: Anxiety and Stress Scale, BSSI: Beck Scale for Suicidal Ideation, FiRST: Fibromyalgia Rapid Screening Tool, FIQ: Fibromyalgia Impact Questionnaire.

Figure 4 Proposed algorithm for an integral evaluation of a patient with RA.

patients with RA after a hip fracture since the activity of the disease increases and there is more functional restriction. ${ }^{78}$

Li et al studied 2923 patients with RA and identified that frailty was mainly associated with a history of osteoporotic fracture and hospitalization. Approximately $4.3 \%$ of the studied sample had osteoporotic fractures and the fragility index was higher compared to patients without fracture. ${ }^{76}$

A higher state of fragility reflects a higher risk of osteoporotic fractures in patients with RA, ${ }^{59,80}$ therefore, it is important to frequently assess frailty using the appropriate tools to detect it in RA and that it can be comprehensively examined for proper clinical and therapeutic management.

\section{Discussion}

The goal of rheumatoid arthritis treatment is focused on reducing the disease activity, and if possible, to reach a complete remission. However, there are comorbidities that are not routinely evaluated in the consultation with the rheumatologist. For this reason, in addition to clinimetry tools for rheumatoid arthritis, it is recommended to include questionnaires that evaluate the different aspects of the disease, such as the Patient Health Questionnaire (PHQ-9) for depression, HADS for anxiety, as well as the identification of sleep and psychiatric disorders. It is also important to evaluate the extra-articular manifestations of the disease such as sarcopenia, fatigue, fibromyalgia, weight changes (Figure 4).

\section{Conclusion}

This review demonstrates different aspects that influence the quality of life and evolution of patients with RA. Depression, anxiety, fatigue, sleep disturbances, suicidal behavior, fibromyalgia, sarcopenia, frailty, cachexia, and obesity are disorders that should be evaluated in patients with RA since their early identification improves the development and impact of these patients. It is evident that the physical domain of quality of life is the most affected in these patients with extraarticular manifestations and this has a significantly negative influence on the psychological domain. It is important to emphasize the importance of a multidisciplinary and comprehensive management in patients with RA and to encourage the creation of studies that analyze the impact of these conditions on the evolution of rheumatoid arthritis.

\section{Copyright/Ethics}

Figures embedded in the article are original, developed by Genessis Maldonado. 


\section{Author Contributions}

All authors made substantial contributions to conception and design, acquisition of data, or analysis and interpretation of data; took part in drafting the article or revising it critically for important intellectual content; gave final approval of the version to be published; and agree to be accountable for all aspects of the work.

\section{Disclosure}

Dr Gustavo Citera report grants, personal fees from Pfizer, during the conduct of the study; grants, personal fees from Pfizer, outside the submitted work. The authors report no other conflicts of interests in this work.

\section{References}

1. Albayrak Gezer İ, Balkarli A, Can B, Bağçaci S, Küçükşen S, Küçük A. Pain, depression levels, fatigue, sleep quality, and quality of life in elderly patients with rheumatoid arthritis. Turkish J Med Sci. 2017;47(3):847-853. doi:10.3906/sag-1603-147

2. Littlejohn EA, Monrad SU, Diagnosis E. Treatment of Rheumatoid Arthritis. Prim Care - Clin off Pract. 2018;45(2):237-255. doi:10.1016/j.pop.2018.02.010

3. Smolen JS, Aletaha D, McInnes IB. Rheumatoid arthritis. Lancet. 2016;388(10055):2023-2038. doi:10.1016/S0140-6736(16)30173-8

4. Shim E-J, Song YW, Park S-H, Lee K-M, Go DJ, Hahm B-J. Examining the relationship between pain catastrophizing and suicide risk in patients with rheumatic disease: the mediating role of depression, perceived social support, and perceived burdensomeness. Int $J$ Behav Med. 2017;24(4):501-512. doi:10.1007/s12529-017-9648-1

5. Fiest KM, Hitchon CA, Bernstein CN, et al. Systematic review and meta-analysis of interventions for depression and anxiety in persons with rheumatoid arthritis. J Clin Rheumatol. 2017;23:425-434. doi:10.1097/RHU.0000000000000489

6. Beşirli A, Jö A, Kaymak D, Özer ÖA. The relationship between anxiety, depression, suicidal ideation and quality of life in patients with rheumatoid arthritis. Psychiatr Q. 2020;91(1):53-64. doi:10.1007/s11126-019-09680-x

7. Kim SY, Chanyang M, Oh DJ, Choi HG. Association between depression and rheumatoid arthritis: two longitudinal follow-up studies using a national sample cohort. Rheumatology. 2020;59 (8):1889-1897. doi:10.1093/rheumatology/kez559

8. Žagar I, Delimar V, Pap M, Perić D, Žerjavić NL, Perić P. Prevalence and correlation of depressive symptoms with functional scores, therapy and disease activity among Croatian patients with rheumatoid arthritis: a preliminary study. Psychiatr Danub. 2018;30(4):452-458. doi:10.24869/psyd.2018.452

9. Vallerand IA, Patten SB, Barnabe C. Depression and the risk of rheumatoid arthritis. Curr Opin Rheumatol. 2019;31(3):279-284. doi:10.1097/BOR.0000000000000597

10. Sováriová Soósová $\mathrm{M}$, Macejová Z, Zamboriová M, Dimunová L. Anxiety and depression in Slovak patients with rheumatoid arthritis. $J$ Ment Heal. 2016;13(14):1-7.

11. Ménard C, Hodes GE, Russo SJ. Pathogenesis of depression: insights from human and rodent studies. Neuroscience. 2016;321:138-162.

12. Hasan Davami M, Baharlou R, Ahmadi Vasmegjani A, et al. elevated IL-17 and TGF- $\beta$ serum levels: a positive correlation between T-helper 17 cell-related pro-inflammatory responses with major depressive disorder. Basic Clin Neurosci. 2016;7(2):137-142. doi:10.15412/J.BCN.03070207
13. Nerurkar L, Siebert S, McInnes IB, Cavanagh J. Rheumatoid arthritis and depression: an inflammatory perspective. Lancet Psychiatry. 2019;6(2):164-173. doi:10.1016/S2215-0366(18)30255-4

14. Matcham F, Rayner L, Steer S, Hotopf M. The prevalence of depression in rheumatoid arthritis: a systematic review and meta-analysis. Rheumatology (Oxford). 2013;52(12):2136-2148. doi:10.1093/rheumatology/ket 169

15. Sturgeon JA, Finan PH, Zautra AJ. Affective disturbance in rheumatoid arthritis: psychological and disease-related pathways. Nat Rev Rheumatol. 2016;12(9):532-542. doi:10.1038/ nrrheum.2016.112

16. Withers MH, Gonzalez LT, Karpouzas GA. Identification and treatment optimization of comorbid depression in rheumatoid arthritis. Rheumatol Ther. 2017;4(2):281-291. doi:10.1007/s40744-017-00724

17. Li Y-C, Chou Y-C, Chen H-C, Lu C-C, Chang D-M. Interleukin-6 and interleukin-17 are related to depression in patients with rheumatoid arthritis. Int $J$ Rheum Dis. 2019;22(6):980-985. doi:10.1111/1756185X.13529

18. Zhang L, Cai P, Zhu W. Depression has an impact on disease activity and health-related quality of life in rheumatoid arthritis: a systematic review and meta-analysis. Int $J$ Rheum Dis. 2020;23(3):285-293. doi:10.1111/1756-185X.13774

19. Intriago M, Maldonado G, Cardenas J, Rios C. Quality of life in Ecuadorian patients with established rheumatoid arthritis. Open Access Rheumatol Res Rev. 2019;11:199-205.

20. Peterson S, Piercy J, Blackburn S, Sullivan E, Karyekar CS, Li N. The multifaceted impact of anxiety and depression on patients with rheumatoid arthritis. BMC Rheumatol. 2019;3(1):1-10. doi:10.1186/ s41927-019-0092-5

21. Abdel-Ahad P, El Chammai M, Fneich A, Issa R, Kabbara W, Richa S. Psychiatric aspects of rheumatoid arthritis: review of literature. Encephale. 2016;42(2):172-176. doi:10.1016/j.encep.2015.12.008

22. Imran MY, Khan SEA, Ahmad NM, Raja SF, Saeed MA, Haider II. Depression in rheumatoid arthritis and its relation to disease activity. Pakistan J Med Sci. 2015;31(2):393-397.

23. Sleath B, Chewning B, De Vellis BM, et al. Communication about depression during rheumatoid arthritis patient visits. Arthritis Care Res. 2008;59(2):186-191. doi:10.1002/art.23347

24. Calandre EP, Rico-Villademoros F, Slim M. Suicidal behaviors in patients with rheumatic diseases: a narrative review. Rheumatol Int. 2018;38(4):537-548. doi:10.1007/s00296-017-3909-9

25. Marrie RA, Walld R, Bolton JM, et al. Psychiatric comorbidity increases mortality in immune-mediated inflammatory diseases. Gen Hosp Psychiatry. 2018;53(06):65-72. doi:10.1016/j. genhosppsych.2018.06.001

26. Kuriya B, Vigod S, Luo J, Widdifield J, Haroon N. The risk of deliberate self-harm following a diagnosis of rheumatoid arthritis or ankylosing spondylitis: a population-based cohort study. PLoS One. 2020;15(2):1-14. doi:10.1371/journal.pone.0229273

27. Treharne GJ, Lyons AC, Kitas GD. Suicidal ideation in patients with rheumatoid arthritis. RESEARCH May Help Identify Patients at High Risk. BMJ. 2000;321(7271):1290.

28. Li Z, Yang Y, Dong C, et al. The prevalence of suicidal ideation and suicide attempt in patients with rheumatic diseases: a systematic review and meta-analysis. Psychol Heal Med. 2018;23 (9):1025-1036. doi:10.1080/13548506.2018.1476724

29. Hewlett S, Hehir M, Kirwan JR. Measuring fatigue in rheumatoid arthritis: a systematic review of scales in use. Arthritis Care Res. 2007;57(3):429-439. doi:10.1002/art.22611

30. Nicassio O, Ormseth S, Custodio M, et al. Model of Fatigue in Patients with Rheumatoid Arthritis. Bone. 2012;39(9):1807-1813.

31. Repping-Wuts H, Van Riel P, Van Achterberg T. Fatigue in patients with rheumatoid arthritis: what is known and what is needed. Rheumatology. 2009;48(3):207-209. doi:10.1093/rheumatology/ken399 
32. Nikolaus S, Bode C, Taal E, Van De Laar MAFJ. Fatigue and factors related to fatigue in rheumatoid arthritis: a systematic review. Arthritis Care Res. 2013;65(7):1128-1146. doi:10.1002/ acr. 21949

33. Irwin MR, Olmstead R, Carrillo C, et al. Sleep loss exacerbates fatigue, depression, and pain in rheumatoid arthritis. Sleep. 2012;35 (4):537-543. doi:10.5665/sleep. 1742

34. Abdul-Rahim R, Hwee-Chen C. Self-reported symptoms of depression, anxiety and stress among patients with Rheumatoid Arthritis in a Malaysian rheumatology centre - prevalence and correlates. Med J Malaysia. 2018;73(4):226-232.

35. Rezaei M, Khormali M, Akbarpour S, Sadeghniiat-Hagighi K, Shamsipour M. Sleep quality and its association with psychological distress and sleep hygiene: a cross-sectional study among pre-clinical medical students. Sleep Sci. 2018;11(4):274-280. doi:10.5935/19840063.20180043

36. Westhovens R, Van Der Elst K, Matthys A, Tran M, Gilloteau I. Sleep problems in patients with rheumatoid arthritis. J Rheumatol. 2014;41(1):31-40. doi:10.3899/jrheum.130430

37. Fenton SAM, van Zanten JJCSV, Duda JL, Metsios GS, Kitas GD. Sedentary behaviour in rheumatoid arthritis: definition, measurement and implications for health. Rheumatol (United Kingdom). 2018;57 (2):213-226.

38. Wolfe F, Michaud K. Effect of body mass index on mortality and clinical status in rheumatoid arthritis. Arthritis Care Res. 2012;64 (10):1471-1479. doi:10.1002/acr.21627

39. Challal S, Minichiello E, Boissier MC, Semerano L. Cachexia and adiposity in rheumatoid arthritis. Relevance for disease management and clinical outcomes. Rev Du Rhum (Edition Fr). 2016;83 (1):19-25.

40. Santo RCE, Fernandes KZ, Lora PS, Filippin LI, Xavier RM. Prevalence of rheumatoid cachexia in rheumatoid arthritis: a systematic review and meta-analysis. J Cachexia Sarcopenia Muscle. 2018;9(5):816-825. doi:10.1002/jcsm.12320

41. Kremers HM, Nicola PJ, Crowson CS, Ballman KV, Gabriel SE. Prognostic importance of low body mass index in relation to cardiovascular mortality in rheumatoid arthritis. Arthritis Rheum. 2004;50 (11):3450-3457. doi:10.1002/art.20612

42. Book C, Karlsson MK, Åkesson K, Jacobsson LTH. Early rheumatoid arthritis and body composition. Rheumatology. 2009;48 (9):1128-1132. doi:10.1093/rheumatology/kep165

43. Moroni L, Farina N, Dagna L. Obesity and its role in the management of rheumatoid and psoriatic arthritis. Clin Rheumatol. 2020;39 (4):1039-1047. doi:10.1007/s10067-020-04963-2

44. Qin B, Yang M, Fu H, et al. Body mass index and the risk of rheumatoid arthritis: a systematic review and dose-response meta-analysis. Arthritis Res Ther. 2015;17(1):1-12. doi:10.1186/ s13075-014-0514-0

45. Feng J, Chen Q, Yu F, et al. Body mass index and risk of rheumatoid arthritis a meta-analysis of observational studies. Med (United States). 2016;95(8):1-8.

46. Lumeng CN, Saltiel AR. Review series Inflammatory links between obesity and metabolic disease. Life Sci. 2011;121(6):2111-2117.

47. Kreps D, Halperin F, Desai S, et al. Association of weight loss with improved disease activity in patients with rheumatoid arthritis: a retrospective analysis using electronic medical record data. Int J Rheumatol. 2018;13(1):1-10.

48. Ellerby N, Mattey DL, Packham J, Dawes P, Hider SL. Obesity and comorbidity are independently associated with a failure to achieve remission in patients with established rheumatoid arthritis. Ann Rheum Dis. 2014;73(11):1-3. doi:10.1136/annrheumdis-2014206254

49. Sandberg MEC, Bengtsson C, Källberg H, et al. Overweight decreases the chance of achieving good response and low disease activity in early rheumatoid arthritis. Ann Rheum Dis. 2014;73 (11):2029-2033. doi:10.1136/annrheumdis-2013-205094
50. Ajeganova S, Andersson ML, Hafström I. Association of obesity with worse disease severity in rheumatoid arthritis as well as with comorbidities: a long-term followup from disease onset. Arthritis Care Res. 2013;65(1):78-87. doi:10.1002/acr.21710

51. Passot C, Mulleman D, Bejan-Angoulvant T, et al. The underlying inflammatory chronic disease influences infliximab pharmacokinetics. MAbs. 2016;8(7):1407-1416. doi:10.1080/ 19420862.2016.1216741

52. Kaeley GS, MacCarter DK, Pangan AL, Wang X, Kalabic J, Ranganath VK. Clinical responses and synovial vascularity in obese rheumatoid arthritis patients treated with adalimumab and methotrexate. J Rheumatol. 2018;45(12):1628-1635. doi:10.3899/ jrheum. 171232

53. Bazzichi L, Giacomelli C, Consensi A, et al. Review One year in review: fibromyalgia. Clin Exp Rheumatol. 2016;34(96):S145-149.

54. Provan SA, Austad C, Halsaa V, Hammer HB, Kvien TK, Uhlig T. Fibromyalgia in patients with rheumatoid arthritis. A 10-year follow-up study, results from the Oslo Rheumatoid Arthritis Register. Clin Exp Rheumatol. 2019;37(1):58-62.

55. Shresher NM, Mohamed AE, Elshahaly MH. Performance of 2016 revised fibromyalgia diagnostic criteria in patients with rheumatoid arthritis. Rheumatol Int. 2019;39(10):1703-1710. doi:10.1007/ s00296-019-04403-8

56. Bucourt E, Martaillé V, Goupille P, et al. A comparative study of fibromyalgia, rheumatoid arthritis, spondyloarthritis, and sjögren's syndrome; impact of the disease on quality of life, psychological adjustment, and use of coping strategies. Pain Med. 2019;:1-10.

57. Gist AC, Guymer EK, Eades LE, Leech M, Littlejohn GO. Fibromyalgia remains a significant burden in rheumatoid arthritis patients in Australia. Int $J$ Rheum Dis. 2018;21(3):639-646. doi:10.1111/1756-185X.13055

58. Duffield SJ, Miller N, Zhao S, Goodson NJ. Concomitant fibromyalgia complicating chronic inflammatory arthritis: a systematic review and meta-analysis. Rheumatology (Oxford). 2018;57(8):1453-1460. doi:10.1093/rheumatology/key075.533

59. Salaffi F, Di Carlo M, Farah S, Di Donato E, Carotti M. Prevalence of frailty and its associated factors in patients with rheumatoid arthritis: a cross-sectional analysis. Clin Rheumatol. 2019;38(7):1823-1830. doi:10.1007/s10067-019-04486-5

60. Durán J, Combe B, Niu J, Rincheval N, Gaujoux-Viala C, Felson DT. The effect on treatment response of fibromyalgic symptoms in early rheumatoid arthritis patients: results from the ESPOIR cohort. Rheumatol (United Kingdom). 2015;54(12):2166-2170.

61. da Chakr RMS, Brenol C, Ranzolin A, et al. Rheumatoid arthritis seems to have DMARD treatment decision influenced by fibromyalgia. Rev Bras Reumatol (English Ed.) 2017;57(5):403-411.

62. Puchner R, Sautner J, Gruber J, et al. High burden of sexual dysfunction in female patients with rheumatoid arthritis: results of a cross-sectional study. J Rheumatol. 2019;46(1):19-26. doi:10.3899/ jrheum. 171287

63. Josefsson KA, Gard G. Women's experiences of sexual health when living with Rheumatoid Arthritis - An explorative qualitative study. BMC Musculoskelet Disord. 2010;11(1):240. doi:10.1186/1471-247411-240

64. Coskun B, Coskun BN, Atis G, Ergenekon E, Dilek K. Evaluation of sexual function in women with rheumatoid arthritis. Urol J. 2013;10 (4):1081-1087.

65. El Miedany Y, El Gaafary M, El Aroussy N, Youssef S, Ahmed I. Sexual dysfunction in rheumatoid arthritis patients: arthritis and beyond. Clin Rheumatol. 2012;31(4):601-606. doi:10.1007/s10067011-1891-2

66. Bay LT, Graugaard C, Nielsen DS, Möller S, Ellingsen T, Giraldi A. Sexual health and dysfunction in patients with rheumatoid arthritis: a cross-sectional single-center study. Sex Med. 2020;8(4):615-630. doi:10.1016/j.esxm.2020.07.004 
67. Saad RB, Fazaa A, Rouached L, et al. Sexual dysfunction and its determinants in women with rheumatoid arthritis. Z Rheumatol. 2020. doi:10.1007/s00393-020-00890-4

68. Cruz-Jentoft AJ, Baeyens JP, Bauer JM, et al. Sarcopenia: european consensus on definition and diagnosis. Age Ageing. 2010;39 (4):412-423. doi:10.1093/ageing/afq034

69. Mochizuki T, Yano K, Ikari K, Okazaki K. Sarcopenia-associated factors in Japanese patients with rheumatoid arthritis: a cross-sectional study. Geriatr Gerontol Int. 2019;19(9):907-912. doi:10.1111/ggi.13747

70. Giles JT, Ling SM, Ferrucci L, et al. Abnormal body composition phenotypes in older rheumatoid arthritis patients: association with disease characteristics and pharmacotherapies. Arthritis Care Res. 2008;59(6):807-815. doi:10.1002/art.23719

71. Petermann-Rocha F, Chen M, Gray SR, Ho FK, Pell JP, CelisMorales C. Factors associated with sarcopenia: a cross-sectional analysis using UK Biobank. Maturitas. 2020;133(12):60-67. doi:10.1016/j.maturitas.2020.01.004

72. Munro R, Capell H. Prevalence of low body mass in rheumatoid arthritis: association with the acute phase response. Ann Rheum Dis. 1997;56(5):326-329. doi:10.1136/ard.56.5.326

73. Doğan SC, Hizmetli S, Hayta E, Kaptanoğlu E, Erselcan T, Güler E. Sarcopenia in women with rheumatoid arthritis. Eur J Rheumatol. 2015;2:57-61. doi:10.5152/eurjrheum.2015.0038

74. Schaap LA, Pluijm SMF, Deeg DJH, Visser M. Inflammatory markers and loss of muscle mass (sarcopenia) and strength. Am J Med. 2006;119(6):526.e9-17. doi:10.1016/j.amjmed.2005.10.049
75. Andrews J, Trupin L, Yelin E, Hough C, Covinski K, Katz P. Frailty and Reduced Physical Function Go Hand in Hand in Adults with Rheumatoid Arthritis: a U.S. Observational Cohort Study. Clin Rheumatol. 2017;36(5):1031-1039.

76. Li G, Chen M, Li X, et al. Frailty and risk of osteoporotic fractures in patients with rheumatoid arthritis: data from the Ontario Biologics Research Initiative. Bone. 2019;127:(February):129-34. doi:10.1016/ j.bone.2019.06.006

77. Andrews JS, Trupin L, Wysham KD, Hough CL, Yelin EH, Katz PP. The impact of frailty on changes in physical function and disease activity among adults with rheumatoid arthritis. ACR Open Rheumatol. 2019;1(6):366-372. doi:10.1002/acr2.11051

78. Briot K, Geusens P, Em Bultink I, Lems WF, Roux C. Inflammatory diseases and bone fragility. Osteoporos Int. 2017;28(12):3301-3314. doi:10.1007/s00198-017-4189-7

79. Güler-Yüksel M, Btjsterbosch J, Ypm G-R, et al. Changes in bone mineral density in patients with recent onset, active rheumatoid arthritis. Ann Rheum Dis. 2008;67(6):823-828. doi:10.1136/ ard.2007.073817

80. Amin S, Gabriel SE, Achenbach SJ, Atkinson EJ, Joseph Melton L. Are young women and men with rheumatoid arthritis at risk for fragility fractures? A population-based study. J Rheumatol. 2013;40 (10):1669-1676. doi:10.3899/jrheum.121493
Open Access Rheumatology: Research and Reviews

\section{Publish your work in this journal}

Open Access Rheumatology Research and Reviews is an international, peer-reviewed, open access journal publishing original research, reports, editorials, reviews and commentaries on all aspects of clinical and experimental rheumatology in the clinic and laboratory including the following topics: Pathology, pathophysiology of rheumatological diseases; Investigation, treatment and management

\section{Dovepress}

of rheumatological diseases; Clinical trials and novel pharmacological approaches for the treatment of rheumatological disorders. The manuscript management system is completely online and includes a very quick and fair peer-review system, which is all easy to use. Visit http://www.dovepress.com/testimonials.php to read real quotes from published authors. 